\title{
Caracterização físico-química de bananas (Musa spp AAB cultivar Prata) da região metropolitana do Vale do Aço - MG
}

\author{
Keslei Rosendo da Rocha ${ }^{1 *}$, Sandro Javier Uribe ${ }^{2}$
}

\begin{abstract}
RESUMO: O monitoramento das propriedades físico-químicas das frutas é fundamental para garantir sua aceitabilidade no mercado. Diferentes plantios de diferentes cidades podem possuir características diferentes. Nesse presente trabalho, bananas do grupo Prata de 4 cidades da região do Vale do Aço foram caracterizadas físicoquimicamente. Foram avaliados o diâmetro, comprimento, massa, polpa, sólidos solúveis totais (SST), potencial hidrogeniônico $(\mathrm{pH})$, umidade, acidez titulável (AT), relação SST/AT, proteína, fibra, lipídio, cinzas, açúcares redutores, não redutores e totais. Quando comparados os resultados para as amostras das quatro diferentes cidades, as amostras da cidade I tiveram a menor acidez titulável $(0,13 \pm 0,02 \%)$ e consequentemente maior relação SST/AT $(165,50 \pm 21,48)$. As amostras da cidade IV tiveram maiores índices de proteína $(4,78 \pm 0,04 \mathrm{~g} / 100 \mathrm{~g})$, fibra $(1,38 \pm 0,02 \mathrm{~g} / 100 \mathrm{~g})$, lipídio $(1,12 \pm 0,02 \mathrm{~g} / 100 \mathrm{~g})$ e cinzas $(2,87 \pm 0,02 \mathrm{~g} / 100 \mathrm{~g})$. Com relação aos açúcares, as amostras da cidade IV também se mostraram como aquelas com maior teor, tanto para os açúcares totais $(21,21 \pm 0,12 \mathrm{~g} / 100 \mathrm{~g})$, para os redutores $(14,44 \pm 0,07 \mathrm{~g} / 100 \mathrm{~g})$ quanto para os não redutores $(6,77 \pm 0,04 \mathrm{~g} / 100 \mathrm{~g})$.
\end{abstract}

Palavras-chave: acidez titulável, açúcares redutores, proteína, lipídio.

\section{Physicochemical characterization of banana fruit (Musa spp AAB - Prata) from metropolitan region of Vale do Aço - MG}

\begin{abstract}
The monitoring of the physicochemical properties of fruits is fundamental to ensure their acceptability in the market. Different plantations of different cities may have different characteristics. In this paper, bananas from the Prata group of 4 cities in the Vale do Aço region were physico-chemically characterized. The fruits were acquired in the four main cities of the region. Samples were analyzed for diameter, length, mass, pulp, total soluble solids (TSS), hydrogenation potential $(\mathrm{pH})$, moisture, titratable acidity (TA), TSS / TA ratio, protein, fiber, lipids, ashes, reducing sugars, non-reducing sugars and total sugars. When comparing the results for the samples from the four different cities, samples from city I had the lowest titratable acidity $(0,13 \pm 0,02 \%)$ and consequently a higher TSS / AT ratio $(165,50 \pm 21,48)$. Samples from city IV had the highest levels of protein $(4,78 \pm 0,04 \mathrm{~g} / 100 \mathrm{~g})$, fiber $(1,38 \pm 0,02 \mathrm{~g} / 100 \mathrm{~g})$, lipid $(1,12 \pm 0,02 \mathrm{~g} / 100 \mathrm{~g})$ and ash $(2,87 \pm 0,02 \mathrm{~g} / 100 \mathrm{~g})$. In relation to sugars, samples from city IV also showed to be those with higher total sugars $(21,21 \pm 0,12 \mathrm{~g} / 100 \mathrm{~g})$, reducing sugars $(14,44 \pm 0,07 \mathrm{~g} / 100 \mathrm{~g})$ and non-reducing sugars $(6,77 \pm 0,04 \mathrm{~g} / 100 \mathrm{~g})$.
\end{abstract}

Keywords: titratable acidity, reducing sugars, protein, lipid.

\section{INTRODUÇÃO}

Segundo Food and Agricultural Organization FAO (2017), a produção mundial de banana no levantamento de 2016 foi da ordem de aproximadamente 113 milhões de toneladas, sendo o Brasil o responsável pela produção estimada de aproximadamente 6 milhões de toneladas, ocupando o quarto lugar mundial na produção dessa fruta no último ano do levantamento. De acordo com o Instituto Brasileiro de Geografia e Estatística IBGE (2016a), os maiores produtores são os estados de São Paulo e Bahia, com produção estimada em 1.089 .820 e 1.084 .548 toneladas, respectivamente.
A região metropolitana do Vale do Aço é composta por quatro principais cidades: Ipatinga, Coronel Fabriciano, Timóteo e Santana do Paraíso, respectivamente (CÂMARA, 2006). Minas Gerais se destaca como o quarto maior produtor de bananas no Brasil, com produção de 773.197 toneladas, sendo o Vale do Aço o responsável pela produção de aproximadamente 5000 toneladas (IBGE, 2016b).

Silva et al. (2013) destacam que, quanto ao grupo, os cultivares comerciais de banana são originados de duas espécies: Musa acuminata e Musa balbisiana. Aquela é responsável pelo genoma

Recebido em 11/06/2018; Aceito para publicação em 09/08/2019

${ }^{1}$ Universidade Federal do Rio Grande do Sul

2 Universidade de Buenos Aires

*E-mail: kesleirosendo@gmail.com 
do tipo A e esta pelo genoma do tipo B. O grupo Prata, por exemplo, é composto por duplo genoma $A$ e um genoma $\mathrm{B}$, pertencendo então ao grupo $\mathrm{AAB}$. Este grupo genômico engloba Prata, Prata Anã, Pacovan e Branca.

Uma das maiores demandas envolvendo o consumo da banana está na duração do tempo de exposição. Uma vez que a casca seja violada, o fruto inicia um processo de escurecimento causado pela oxidação dos fenóis existentes no fruto pela enzima polifenoloxidase, o que leva à produção de quininas que se polimerizam formando melanina, esta responsável pelo escurecimento (CASTRO, ARENILLO, 2016). Para serem desenvolvidos aditivos que retardem essa reação de oxidação, as propriedades físico-químicas devem ser observadas tanto antes quanto depois da adição, com objetivo de monitoramento das mudanças nessas propriedades.

Uma das formas de se prolongar o tempo de vida útil da banana é o uso da secagem. Esta tem sido estudada por se mostrar eficiente em não alterar as características sensoriais e nutritivas (BARBOSA, LOBATO, 2016). A operação de secagem é considerada um dos métodos mais simples e econômicos na preservação dos alimentos, uma vez que a remoção da água desfavorece a maioria das reações de oxidação (SILVA, 2017). O principal interesse pelos processos de desidratação é pela possiblidade de reconstituição instantânea, principalmente considerando que a banana seja um alimento de preparo rápido. Independente se o processo é por adição de conservantes inibidores de oxidação ou processos como a secagem, as propriedades físico-químicas antes e após os processos de conservação devem ser analisadas e registradas, garantindo que as propriedades sensoriais e nutritivas se mantenham, favorecendo assim a aceitação do produto por parte dos consumidores.

O objetivo desta pesquisa foi determinar as propriedades físico-químicas de bananas do grupo Prata comercializadas e consumidas na região metropolitana do Vale do Aço, Minas Gerais, para posterior comparação com bananas do mesmo grupo em diferentes regiões do Brasil.

\section{MATERIAL E MÉTODOS}

As amostras de bananas foram coletadas e rotuladas conforme tabela 1 abaixo. As amostras foram coletadas nos plantios das respectivas cidades. O nível de maturação para todas as amostras era 6 (totalmente maduro), conforme escala Von Loesecke (1950).

\begin{tabular}{ccc}
\multicolumn{3}{l}{ Tabela 1. Identificação e N amostral de cada cidade. } \\
\hline Cidade & Rótulo & $\mathrm{N} \mathrm{amostral}^{*}$ \\
\hline Santana do Paraíso & I & 50 \\
Timóteo & II & 50 \\
Coronel Fabriciano & III & 50 \\
Ipatinga & IV & 50 \\
\hline
\end{tabular}

${ }^{*} \mathrm{~N}$ amostral é o número de bananas coletadas.

O diâmetro, comprimento, massa e \% polpa foram determinados sobre uma amostra de 50 unidades de cada uma das cidades onde foram adquiridas. O diâmetro e o comprimento foram medidos com o auxílio de uma régua métrica. A massa foi determinada com o auxílio de uma balança analítica (Shimadzuay 220). Já a \% polpa foi determinada conforme equação 1 a seguir:

$$
\left.\% \text { polpa }=\frac{\text { Mc }}{\text { Mc+Mp }} \times 100 \quad \text { (Equação } 1\right)
$$

Onde:

$\mathrm{Mc}=$ massa da casca

$\mathrm{Mp}=$ massa de polpa

Para as determinações dos sólidos solúveis totais (SST), $\mathrm{pH}, \%$ umidade, \% acidez titulável (AT) e a razão SST/AT, foram retirados ao acaso 7 unidades de cada cidade. Para cada uma das cidades, as 7 unidades escolhidas ao acaso foram trituradas em liquidificador até consistência constante. Para diluição foi mantida a proporção 1:1 entre água destilada e massa das 7 unidades. Os SST foram determinados com o auxílio de um refratômetro portátil (RHB 32). O potencial hidrogeniônico $(\mathrm{pH})$ foi determinado com o auxílio de um pHmetro (Marte MB10) conforme Association of Official Agricultural Chemists - AOAC (1995). A umidade (\%) foi determinada por aquecimento em estufa (SX 450) a $70{ }^{\circ} \mathrm{C}$ até massa constante (AOAC, 1995). A acidez titulável foi determinada conforme metodologia da AOAC (1995), que consistiu em reação de neutralização usando $\mathrm{KOH}(0,1 \mathrm{M})$ e os resultados foram expressos em \% de ácido málico. A razão SST/AT foi calculada conforme equação: Sólidos solúveis totais/ acidez titulável.

A determinação de proteína foi feita conforme técnica AOAC 992.23, fibra conforme Instituto Adolfo Lutz (2008), lipídio conforme AOAC 933.05 e cinzas conforme AOAC 940.26 (AOAC, 1992). Para proteína, usou-se o método Kjeldahl em um destilador de nitrogênio (TE-0365) e posterior conversão para teor de proteínas com o fator de conversão 6.25 (AOAC, 1995). Para determinação de lipídio, usou-se a técnica de extração em Soxhlet com a amostra em cápsula de celulose e o solvente éter de petróleo (30-70, Synth) em refluxo. O conteúdo na cápsula após o período total de extração por refluxo foi usado para determinação de fibra. 
Para determinação de cinzas usou-se o forno mufla (MA385/3) a $550{ }^{\circ} \mathrm{C}$ até peso constante.

Em relação aos açúcares, esses foram determinados a partir dos triturados de cada uma das 7 amostras para cada uma das cidades. Para isso, $1 \mathrm{~g}$ de cada um dos triturados foi diluído em balão volumétrico de $25 \mathrm{~mL}$ de capacidade. O solvente utilizado foi água destilada. O conteúdo de cada balão foi filtrado em papel de filtro e no filtrado foram determinados os açúcares. A metodologia utilizada foi a de Nelson (1945), que consistiu no preparo de 4 diferentes grupos de reagentes para reação com $1 \mathrm{~mL}$ do filtrado. Hidrolisou-se o filtrado para a determinação dos açúcares totais. Para determinação dos açúcares não redutores foi feito o cálculo proposto: (açúcares totais - açúcar redutor) x 0.95. A leitura foi feita em $520 \mathrm{~nm}$ em espectrofotômetro de absorção molecular UV-Vis (BiospectroSp 220). Para o cálculo dos açúcares foi feito previamente uma curva de glicose, que gerou uma equação linear com $\mathrm{R}^{2}=0,998$. Os açúcares foram expressos em $\mathrm{g} / 100 \mathrm{~g}$ de polpa.

\section{RESULTADOS E DISCUSSÃO}

Na tabela 2 abaixo seguem as determinações para diâmetro médio, comprimento médio, massa média e $\%$ polpa das 50 unidades avaliadas para cada cidade.

Com o auxílio da tabela 2 foi observado que, quanto ao diâmetro, estatisticamente as unidades das cidades I e IV se mostraram com os maiores diâmetros médios $(3,73 \pm 0,02 \mathrm{~cm}$ e 3,76 $\pm 0,06 \mathrm{~cm}$, respectivamente). Quando ao comprimento, as unidades da cidade IV se mostraram como as mais compridas $(21,23 \pm 0,12 \mathrm{~cm})$. As unidades da cidade IV se mostraram ainda como as de maior massa média $(168,95 \pm 0,52 \mathrm{~g})$. Descontadas as cascas, a \% média que representou quanto do fruto era composto pela polpa foi maior nas unidades da cidade II $(78,33 \pm 1,32 \%)$.

Ribeiro et al. (2012) determinaram para a banana prata, massa, diâmetro e comprimento igual a 135,08 g, 3,78 cm e 16,62 cm, respectivamente. Já Pereira et al. (2011) determinaram para o mesmo tipo de bananas, diâmetro, comprimento, massa e \% de polpa igual a $4,10 \mathrm{~cm}, 16,90 \mathrm{~cm}, 140,21 \mathrm{~g}$ e $62,10 \%$, respectivamente. Em ambos os casos os valores determinados por estes autores foram próximos àqueles determinados neste presente estudo.

Tabela 2. Caracterização física das unidades avaliadas

\begin{tabular}{ccccc}
\hline Cidade & Diâmetro $(\mathrm{cm})$ & Comprimento $(\mathrm{cm})$ & Massa $(\mathrm{g})$ & $\%$ polpa \\
\hline I & $3,73 \pm 0,02 \mathrm{a}$ & $19,15 \pm 0,18 \mathrm{~b}$ & $145,80 \pm 0,32 \mathrm{~b}$ & $72,18 \pm 1,02 \mathrm{~b}$ \\
II & $3,58 \pm 0,10 \mathrm{ab}$ & $18,98 \pm 0,10 \mathrm{~b}$ & $124,89 \pm 0,18 \mathrm{~d}$ & $78,33 \pm 1,32 \mathrm{a}$ \\
III & $3,54 \pm 0,08 \mathrm{~b}$ & $19,24 \pm 0,21 \mathrm{~b}$ & $126,71 \pm 0,22 \mathrm{c}$ & $67,28 \pm 2,45 \mathrm{c}$ \\
IV & $3,76 \pm 0,06 \mathrm{a}$ & $21,23 \pm 0,12 \mathrm{a}$ & $168,95 \pm 0,52 \mathrm{a}$ & $70,44 \pm 1,18 \mathrm{bc}$ \\
\hline
\end{tabular}

Letras iguais na mesma coluna indicam que não houve diferença significativa pelo teste Tukey com $\alpha=0,05$

Na tabela 3 abaixo estão os resultados para as análises de sólidos solúveis totais, $\mathrm{pH}$, umidade, acidez titulável e a razão sólidos solúveis / acidez titulável.

Com o auxílio da tabela 3 foi possível identificar que, para os sólidos solúveis totais, as unidades analisadas da cidade IV se mostraram como aquelas com maior quantidade de SST $\left(22,84 \pm 0,57^{\circ}\right.$ Brix $)$. Já quanto ao $\mathrm{pH}$, as unidades das cidades I e II se mostraram com valores estatisticamente iguais, com $\mathrm{pH}$ na faixa $5(5,18 \pm 0,16$ e $5,12 \pm 0,13$, respectivamente), assim como as unidades das cidades III e IV também se mostraram com $\mathrm{pH}$ estatisticamente iguais, porém na faixa 4 $(4,78 \pm 0,06$ e 4,66 $\pm 0,14$, respectivamente). Para a umidade, as unidades da cidade II se mostraram como as que possuíam o maior teor de água $(74,22 \pm 0,47 \%)$. Para a acidez titulável, as unidades da cidade III e IV se mostraram com a maior \% $(0,22 \pm<0,01$ e $0,23 \pm 0,02 \%$, respectivamente $)$, sendo essa acidez dada em \% de ácido málico. A razão entre SST/AT se mostrou alta nas amostras de todas as cidades devido à baixa acidez titulável. Por esse mesmo motivo, as unidades da cidade I (por se mostrarem com menor valor de AT) tiveram a maior razão SST/AT $(165,50 \pm 21,48)$.

Silva et al. (2017) determinaram valores de SST, $\mathrm{pH}$, umidade, AT e SST/AT iguais a $22,00{ }^{\circ}$ Brix, $4,55,68,50 \%, 0,18 \%$ e 122,2, respectivamente. Já Pereira et al. (2011) determinaram SST, pH, AT e SST/AT iguais a $23,30{ }^{\circ}$ Brix, $4,59,0,25 \%$ e 93,5 , respectivamente. Em ambos os casos os valores determinados pelos autores supracitados foram próximos àqueles determinados neste presente estudo.

Tabela 3. Primeira caracterização físico-química

\begin{tabular}{cccccc}
\hline Cidade & SST $\left({ }^{\circ}\right.$ Brix $)$ & $\mathrm{pH}$ & Umidade $(\%)$ & AT $(\%)$ & SST/AT \\
\hline I & $21,23 \pm 0,55 \mathrm{~b}$ & $5,18 \pm 0,16 \mathrm{a}$ & $73,12 \pm 0,50 \mathrm{ab}$ & $0,13 \pm 0,02 \mathrm{c}$ & $165,50 \pm 21,48 \mathrm{a}$ \\
II & $22,18 \pm 0,75 \mathrm{ab}$ & $5,12 \pm 0,13 \mathrm{a}$ & $74,22 \pm 0,47 \mathrm{a}$ & $0,17 \pm<0,01 \mathrm{~b}$ & $130,57 \pm 4,26 \mathrm{~b}$ \\
III & $22,47 \pm 0,57 \mathrm{ab}$ & $4,78 \pm 0,06 \mathrm{~b}$ & $69,12 \pm 3,33 \mathrm{~b}$ & $0,22 \pm<0,01 \mathrm{a}$ & $102,14 \pm 2,59 \mathrm{bc}$ \\
IV & $22,84 \pm 0,57 \mathrm{a}$ & $4,66 \pm 0,14 \mathrm{~b}$ & $71,02 \pm 0,22 \mathrm{ab}$ & $0,23 \pm 0,02 \mathrm{a}$ & $99,66 \pm 6,21 \mathrm{c}$ \\
\hline
\end{tabular}

Letras iguais na mesma coluna indicam que não houve diferença significativa pelo teste Tukey com $\alpha=0,05$ 
SST = Sólidos solúveis totais; $\mathrm{pH}=$ potencial hidrogeniônico; $\mathrm{AT}$ = acidez titulável.

$\mathrm{Na}$ tabela 4 abaixo estão os resultados das caracterizações de proteína, fibra, lipídio e cinzas. Esses parâmetros foram determinados de forma centesimal, resultando em gramas/ $100 \mathrm{~g}$ analisados.
Com o auxílio da tabela 4 foi possível observar que, para o teor de proteína, fibra, lipídio e cinzas, as unidades analisadas da cidade IV se mostraram como aquelas com as maiores quantidades dos parâmetros analisados para cada $100 \mathrm{~g}$ de amostra.

Tabela 4. Segunda caracterização físico-química

\begin{tabular}{ccccc}
\hline \multirow{2}{*}{ Cidade } & \multicolumn{5}{c}{$\mathrm{g} / 100 \mathrm{~g}$ polpa } \\
\cline { 2 - 5 } & Proteína & Fibra & Lipídio & Cinzas \\
\cline { 2 - 5 } I & $3,80 \pm 0,07 \mathrm{~d}$ & $1,03 \pm 0,01 \mathrm{~b}$ & $0,55 \pm 0,02 \mathrm{c}$ & $2,05 \pm 0,05 \mathrm{c}$ \\
II & $4,51 \pm 0,05 \mathrm{c}$ & $0,79 \pm 0,02 \mathrm{c}$ & $0,60 \pm 0,02 \mathrm{c}$ & $2,14 \pm 0,01 \mathrm{c}$ \\
III & $4,26 \pm 0,03 \mathrm{~b}$ & $1,02 \pm 0,01 \mathrm{~b}$ & $0,70 \pm 0,02 \mathrm{~b}$ & $2,76 \pm 0,03 \mathrm{~b}$ \\
IV & $4,78 \pm 0,04 \mathrm{a}$ & $1,38 \pm 0,02 \mathrm{a}$ & $1,12 \pm 0,02 \mathrm{a}$ & $2,87 \pm 0,02 \mathrm{a}$ \\
\hline
\end{tabular}

Letras iguais na mesma coluna indicam que não houve diferença significativa pelo teste Tukey com $\alpha=0,05$

Na tabela 5 abaixo estão os resultados para a caracterização do açúcar total, redutor e não redutor. Os resultados foram expressos em gramas de açúcar para cada $100 \mathrm{~g}$ de amostra (centesimal).

Com o auxílio da tabela 5 e figura 1 abaixo, observou-se que, para as unidades testadas provindas das diferentes cidades, aquelas obtidas a partir da cidade IV foram as que apresentaram, em média, os maiores valores estatísticos tanto para o açúcar redutor $(14,44 \pm 0,07 \mathrm{~g} / 100 \mathrm{~g})$, para o açúcar não redutor $(6,77 \pm 0,04 \mathrm{~g} / 100 \mathrm{~g})$, quanto para o açúcar total $(21,21 \pm 0,12 \mathrm{~g} / 100 \mathrm{~g})$.

Rocha e Uribe (2018) determinaram a composição dos açúcares redutores e não redutores presentes em bananas pratas no mesmo grau de maturação das bananas utilizadas neste presente estudo. Os autores observaram a presença de $9,12 \mathrm{~g}$ de glicose, $8,74 \mathrm{~g}$ de frutose e 2,63 $\mathrm{g}$ de sacarose totalizando assim $20,49 \mathrm{~g}$ de açúcar total para cada $100 \mathrm{~g}$ de polpa de banana prata em grau de maturação $6 \mathrm{~g}$ de polpa de banana prata em grau de maturação igual a 6 (VON LOESECKE, 1950). Já Ribeiro et al. (2012) determinaram 15,47 g de açúcares redutores e $1,20 \mathrm{~g}$ de não redutores, totalizando $16,67 \mathrm{~g}$ de açúcar total para cada $100 \mathrm{~g}$ de polpa de banana prata madura.

Em ambos os casos a quantidade de açúcares redutores, não redutores e, consequentemente, de açúcares totais, foi muito próxima àquela determinada no presente estudo.

Tabela 5. Terceira caracterização físico-química

\begin{tabular}{cccc}
\hline \multirow{2}{*}{ Cidade } & g de glicose / 100 g de polpa & & Açúcar não redutor \\
\cline { 2 - 4 } & Açúcar total & Açúcar redutor & $3,78 \pm 0,04 \mathrm{c}$ \\
I & $14,33 \pm 0,06 \mathrm{~d}$ & $10,55 \pm 0,02 \mathrm{~d}$ & $5,95 \pm 0,02 \mathrm{~b}$ \\
II & $18,32 \pm 0,01 \mathrm{~b}$ & $12,36 \pm 0,01 \mathrm{~b}$ & $3,38 \pm 0,04 \mathrm{~d}$ \\
III & $15,37 \pm 0,01 \mathrm{c}$ & $11,98 \pm 0,03 \mathrm{c}$ & $6,77 \pm 0,04 \mathrm{a}$ \\
\hline
\end{tabular}

Letras iguais na mesma coluna indicam que não houve diferença significativa pelo teste Tukey com $\alpha=0,05$

Na figura 1 abaixo, foram feitas as comparações estatísticas entre os açúcares e as cidades de onde as unidades foram coletadas.

A cidade IV se mostrou estatisticamente como a de maiores índices nas propriedades diâmetro, comprimento, massa, sólidos solúveis totais, acidez titulável, proteína, fibra, lipídio, cinza, açúcares redutores, não redutores e totais.

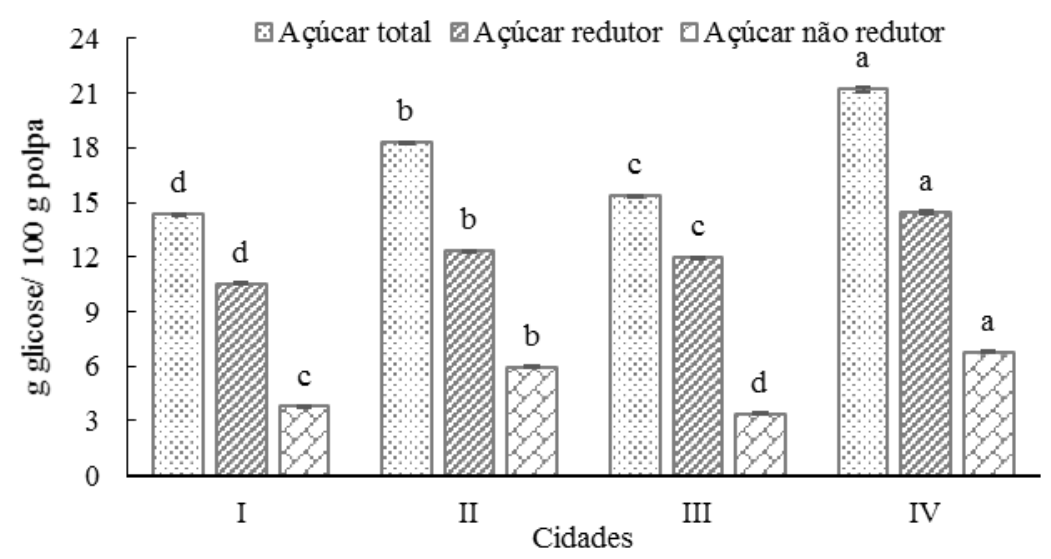

ACSA, Patos-PB, v.15, n.4, p.269-274, Outubro-Dezembro, 2019, ISSN: 1808-6845 
Figura 1. Comparação entre as quantidades estatísticas de açúcares nas amostras das diferentes cidades. Letras iguais no topo das colunas de um mesmo grupo indicam que não houve diferença significativa pelo teste Tukey com $\alpha=0,05$

$\mathrm{Na}$ tabela 6 abaixo foram feitas comparações entre os resultados do presente trabalho e outros encontrados para trabalhos com temática similar na literatura atual. Os valores da presente pesquisa estão representados como a média dos resultados para as amostras das 4 cidades. Os valores dos parâmetros para os demais autores consistiram na média dos valores por eles determinados para bananas do mesmo tipo e subtipo utilizados neste presente estudo.

Tabela 6. Comparações das literaturas para os resultados apresentados

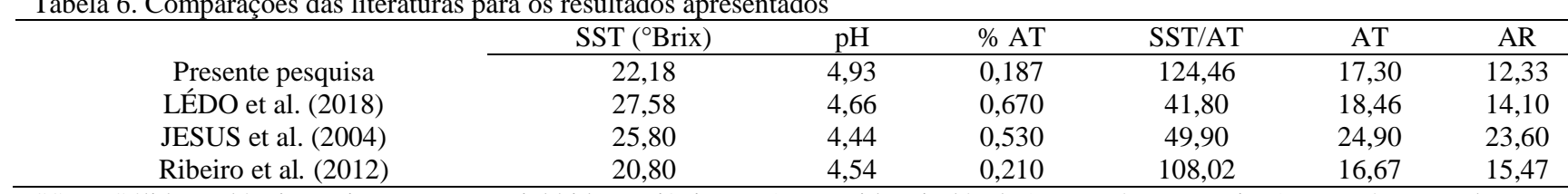

$\mathrm{SST}=$ Sólidos solúveis totais $; \mathrm{pH}=$ potencial hidrogeniônico; \%AT = acidez titulável; AT = açúcares totais; AR = açúcares redutores

Com o auxílio da tabela 6 , foi possível observar que os parâmetros SST e pH se mostraram muito próximos àqueles das literaturas comparadas. A acidez titulável deste presente trabalho se mostrou próxima àquela determinada por Ribeiro et al. (2012), mas abaixo da acidez determinada pelos outros autores citados. Por causa da baixa \%AT, a razão SST/AT deste presente trabalho se mostrou mais elevada do que aquelas razões registradas nas literaturas consultadas. Com relação aos açúcares totais e redutores, Jesus et al. (2004) determinaramvalores muitos maiores que os demais autores e do que o presente trabalho.

\section{CONCLUSÃO}

Embora todas as amostras analisadas tenham sido de frutos do mesmo grupo (Musa spp AAB cultivar Prata), foram identificadas diferenças significativas em suas propriedades físico-químicas entre as cidades pesquisadas.

Plantios em terrenos de diferentes cidades, mas na mesma região geográfica, possibilitaram diferentes resultandos, possivelmente alcançados pelo uso de diferentes tipos de adubos.

Quando comparados com as literaturas com a mesma temática, foi possível afirmar que houve uma heterogeneidade nos valores determinados, apontando para a possibilidade de que, independente de pertencerem a um mesmo grupo, as propriedades físícas e químicas podem ser muito diferentes para cada cultivo.

\section{AGRADECIMENTOS}

Os autores agradecem à CAPES pelo financiamento, à Universidade Federal do Rio Grande e à Universidade Presidente Antônio Carlos pela infraestrutura.

\section{REFERÊNCIAS}

AOAC - Association of Official Analytical Chemists. Official methods of analysis. 10. ed. Washington: AOAC Internacional, 1992, $1025 \mathrm{f}$.

AOAC - Association of Official Analytical Chemists. Official methods of analysis. 16. ed. Washington: AOAC Internacional, 1995, $1025 \mathrm{f}$.

BARbOSA, T. A., LOBATO, F. S. Determinação da cinética de secagem de produtos alimentícios usando algoritmos genéticos. Revista de Agricultura Neotropical, Cassilândia, v. 3, n. 3, p. 28-37, 2016.

CAMARA. Legislação citada anexada pela Coordenação de estudos legislativos - cedi: Lei complementar $\mathrm{n}^{\mathbf{0}}$ 90, de 12 de janeiro de 2006. 2006. Disponível em: <http://www.camara.gov.br/sileg/integras /434777.pdf >. Acesso em: 26 ago. 2018.

CASTRO JÚNIOR, M. A., ARENILLO, S.A. Acceptability of Musa Balbisiana (saba banana) pure in two treatments in making ice cream. Asia Pacific Journal of Multidisciplinary Research, Batangas, v. 4, n. 4, p. 29-33, 2016.

FAO. Food and Agriculture Organization. 2017. Banana Statistical Compendium 2015-2016. Disponível em: <http://www.fao.org/3/a-i7409e.pdf>. Acesso em 26 Ago. 2018.

IBGE. Instituto Brasileiro de Geografia e Estatística. Tabela 5457 - Área plantada ou destinada à colheita, área colhida, quantidade produzida, rendimento médio e valor da produção das lavouras temporárias e permanentes por município. 2016a. Disponível em: <https://sidra.ibge.gov.br/tabela/5457>. Acesso em: 26 ago. 2018.

IBGE. Instituto Brasileiro de Geografia e Estatística. Tabela 5457 - Área plantada ou destinada à colheita, área colhida, quantidade produzida, rendimento médio e valor da produção das lavouras temporárias e permanentes por unidade federativa. 2016b. Disponível em: <https://sidra.ibge.gov.br/tabela/5457>. Acesso em: 26 ago. 2018. 
Instituto Adolfo Lutz. Métodos físico-químicos para análise de alimentos. 4. ed. São Paulo-SP: Instituto Adolfo Lutz, 2008. 1000f.

JESUS, S. C., FOLEGATTI, M. I. S., MATSUURA, F. C. A. U., CARDOSO, R. L. Caracterização física e química de frutos de diferentes genótipos de bananeira. Bragantia, Campinas, v. 68, n. 3, p. 315-323, 2004.

LÉDO, A. S., SILVA, T. N., MARTINS, C. R., SILVA, A. V. C., LÉDO, C. A. S., AMORIM, E. P. Caracterização físico-química de frutos de bananeira por procedimentos uni e multivariados. Bioscience Journal, Uberlândia, v. 34, n. 1, p. 24-33, 2018.

NELSON, N. A. A. Photometric adaptation of Somogyi method for determination of glucose. The Journal of Biological Chemistry, Cincinnati, v. 153, p. 375-380, 1944.

PEREIRA, V. M. O., MORAIS, P. L. D., AMBRÓSIO, M. M. Q. WANDERLEY, J. A. C., SOUZA, J. S. Qualidade pós-colheita de cultivares de bananas comercializadas em Pombal-PB. Revista Verde de Agroecologia e Desenvolvimento Sustentável, Mossoró, v. 5, n. 1, p. 49-55, 2011.
RIBEIRO, L. R., OLIVEIRA, L. M., SILVA, S. O., BORGES, A. L. Caracterização física e química de bananas produzidas em sistemas de cultivo convencional e orgânico. Revista Brasileira de Fruticultura, Jaboticabal, v. 34, n. 3, p. 774 - 782, 2012.

ROCHA, K. R., URIBE, S. J. Relação amido e açúcares solúveis durante o processo de maturação da banana prata. Tecnologia e Ciência Agropecuária, João Pessoa, v. 12, n. 2, p 51-56, 2018.

SILVA, M. I., MELO, I. L. F., ALVES, T. L., MARTINS, J. N., RIBEIRO, M. C. M., SOUZA, F. C. Avaliação físico-química de bananas (Musa sapientum cultivar prata) desidratadas. Revista Semiárido De Visu, Petrolina, v. 5, n. 2, p. 73-79, 2017.

SILVA, S. O., AMORIM, E. P., SEREJO, J. A. S., FERREIRA, C. F., RODRIGUEZ, M. A. D. Melhoramento genético da bananeira: estratégias e tecnologias disponíveis. Revista Brasileira de Fruticultura, Jaboticabal, v. 35, n. 3, p. 919-931, 2013.

VON LOESECKE, H. Bananas, 2. ed. New York: InterScience, $1950,189 \mathrm{p}$. 